\title{
Anemia in Urban Male Replacement Blood Donors. A Cause for Concern N Raza
}

\begin{abstract}
Objectives: To gain baseline knowledge about frequency, severity and types of anemia among prospective urban replacement blood donors.

Methods: A prospective study was carried out at the blood bank of a tertiary care hospital in Karachi, Pakistan, on temporarily rejected male blood donors due to anemia based on pre-donation complete blood counts. Severity of anemia was determined according to WHO criteria into mild, moderate and severe. Type of anemia was graded based on MCV values of $<80 \mathrm{fL}, 80-100 \mathrm{fL}$ and $>80 \mathrm{fL}$ into microcytic, normocytic and macrocytic anemia.Prevalence of anemia was also calculated.

Results: Among 18539 male replacement donors during one year, deferrals due to anemia were 1445[56.07\%] out of a total of 2577 temporary rejections. Prevalence of anemia was found to be $7.8 \%$ among male population. Mild anemia was found in $80.1 \%$ donors and the commonest type of anemia based on MCV was hypochromic, microcytic [66.6\%]. A significant correlation was found between microcytic anemia with disease severity [p value0.009] and age group 30-40 years [p value0.000].

Conclusion: A high prevalence of anemia among male replacement donors, not associated with frequency of donation signifies deteriorating health status of male population with concomitant regular loss of whole blood donations. Knowledge of cause of anemia is vital to guide the recruitment strategy for whole blood donors.
\end{abstract}

Keywords: Anemia, blood donors, male replacement, temporary deferrals

From: Department of Hematology, Liaquat National Hospital Stadium Road, Karachi, Pakistan.

Correspondence: Dr N Raza, 160-N Block 3 PECHS Kashmir Road, Karachi, Pakistan. E-mail: drnailarahman@yahoo.com

West Indian Med J

DOI: 10.7727.wimj.2015.309 


\section{INTRODUCTION}

Demand for blood component therapy is steadily growing in Pakistan due to continuous expansion in population which currently stands at 182 million. Liaquat National Hospital is located in the heart of metropolis city Karachi and is a750 bedded largest tertiary care private institute for undergraduate and post graduate studies. It caters approximately 25,000 emergencies, 60,000 inpatients and over 260,000 outpatients each year. Replacement donors are the backbone of our country's donor pool as voluntary donations are only $10 \%$.(1)Donor selection criteria play a pivotal role in donor recruitment, an important component being evaluation of hemoglobin, performed by various standard techniques. Both World Health Organization guidelines[WHO] and American Association of Blood Bank[AABB] have specified cut off hemoglobin[Hb] levels for donor selection but ranges for Total Leucocyte Count $[\mathrm{TLC}]$ and platelet counts are not mentioned, rather blood transfusion services are encouraged to set their own ranges for blood cell parameters based on their population demographics.(2,3) A neglected part of donor loss comprises of temporary rejections based on low hemoglobin which acts as a de-motivational factor and adversely affects the donor return rate.(4). Our study was conducted at the blood bank of the hospital with the objective to determine the prevalence, severity and types of anemia common in otherwise healthy blood donors and to look for an association between frequency of donation and age group with low hemoglobin. 


\section{METHODOLOGY}

A prospective study was carried out at the blood bank of Liaquat National Hospital, Karachi from January 2014 to December 2014. As a part of pre-donation screening, $2.7 \mathrm{ml}$ venous blood was collected in EDTA[ethylene di-amine tetra acetic acid] tube from all donors and CBC was run on Nihon Kohden MEK-6410K hematology analyzer following appropriate controls. Acceptable hematological ranges for donor selection were in accordance with AABB guidelines and set as follows: $\mathrm{Hb}=12.5-17 \mathrm{gm} / \mathrm{dl}, \mathrm{TLC}=4.0-11 \times 10^{\wedge} 9 / 1$, platelet count $=150-400 \times 10^{\wedge} 9 / 1$ Severity of anemia was determined according to WHO criteria into mild, moderate and severe.(5) Type of anemia was graded based on MCV values of $<80 \mathrm{fL}, 80-100 \mathrm{fL}$ and $>80 \mathrm{fL}$ into microcytic, normocytic and macrocytic anemia respectively.(6) Data was analyzed using SPSS v. 21. Quantitative variables including age, hemoglobin and MCV were reported in terms of mean and standard deviation. Frequencies and percentages were used to report categorical variables including severity of anemia, types of anemia and frequency of donation. Significant associations between age, type, severity of anemia and frequency of donation were explored using spearman rank correlation test. P-values less than 0.05 were considered statistically significant.

The study protocol was approved by the institutional review board of Liaquat National Hospital and Medical College. We obtained informed written consent from all donors after the study protocol had been explained to them. 


\section{RESULTS}

From January 2014 to December 2014 the blood bank of Liaquat National Hospital received a total of 18,658 donors to donate blood of which 18,484 [99.06\%] were replacement donors and only $174[0.93 \%$ ] came for voluntary donations. Male donors were 18539 [99.36\%] while female donors were $119[0.63 \%] .2,577$ [13.81\%] donors were found unfit on clinical and hematological assessment prior to donation. Based on CBC findings, 56.07\% male replacement donors were deferred due to low hemoglobin [1445 out of 2577]. Prevalence of anemia was calculated as $7.8 \%$ among male population. Mild anemia was found in $80.1 \%$ donors and the commonest type of anemia based on MCV was hypochromic, microcytic [66.6\%]. Donor demographics are shown in Table 1.

Spearman correlation test was used to determine the association between anemia's severity, type and age groups. A significant correlation was found between microcytic anemia with disease severity [p value 0.009$]$ and age group 30-40 years [p value0.000]. However association between severities of anemia with frequency of donation was insignificant. [Table2]

\section{DISCUSSION}

In developing countries like Pakistan which rely heavily on replacement donations, high prevalence of anemia [7.8\%] among its male donor population is a major cause of concern. Furthermore, presence of predominant hypo-chromic morphology not associated with frequency of donation signifies a deteriorating health status of male population with concomitant regular loss of whole blood donations. 
Our results showed a temporary blood donor rejection rate of $13.8 \%$ which falls within the acceptable donor deferral rate range of 5-10\%.Tufail et al from Pakistan have quoted a similar figure of 13.58\%. (7) Analogous results are reported from America, Europe and other regional countries.Zou et al. [12.8\%] Custer et al. (13.6\%) Arslan et al. [14.6\%]Bahadur et al.[9\%]. (8, 9, $10,11)$

Our high rate of temporary rejections among male replacement donors due to low hemoglobin [56.07\%]corresponds to the results of a large study by Custer et al based on 3.9 million donorsquoting low hematocrit as the commonest cause of temporary deferrals [76\%]; however gender distribution is not mentioned.(12)In contrast, two local studies from northern parts of Pakistan have reported a relatively low incidence of anemia among donors [36.1\% and $13.3 \%$ ] discrepancy attributed to their small study population[n=1833 and $3617](7,13)$.However their results are comparable to other studies both western and regional.Di Lorenzo Oliveira C et al. [22.6\%] from Brazil, Charles et al. [22.2\%] from Trinidad and Tobago and Arslan et al. [20.7\%] from Turkey. (14,15,10) Interestingly Rabeya et al. from Malaysia and Agnihotri et al. from western India have reported a much higher incidence of anemia among their donors as $40.7 \%$ and $55.8 \%$ respectivelywhich is understandable as half of their deferred donor population were pre-menopausal females. $(16,17)$

$80.1 \%$ of our rejected male donors suffered from mild anemia which is similar to $82.9 \%$ reported by Bahadur et al from Indiabut their minimum cut off limit for mild anemia was hemoglobin level of $10 \mathrm{gm} / \mathrm{dL}$ against our $11 \mathrm{gm} / \mathrm{dL}$. (18)If we consider their minimum range then our donor population with mild anemia jumps to $87 \%$ which is an alarmingly high figure. 
Iron deficiency changes are seen initially as normochromic anemia which evolves into hypochromic microcytic type as disease advances. Our results showed hypochromic microcytic anemia as the leading morphologic finding [66.60\%] followed by normochromic anemia [31.7\%]. Almost paradoxical results are reported by Bahadur et al from India which is 74\% normochromic anemia and 14.6\% hypochromic microcytic anemia.(18) A study conducted on Iranian blood donors by Javadzadeh SH et al. reported iron deficiency anemia; manifested morphologically as microcytic anemia in $16 \%$ of male donors.(19) da Silva et al. from Brazil confirmed the presence of iron deficiency in $25 \%$ of its rejected male donors and $37.5 \%$ of its total rejected donors.(20)Hence it can be inferred that presence of predominant microcytic morphology indicate advanced iron deficiency changes among our male donors.

An expected finding reported in this study is a significant correlation between severity of anemia and microcytic type seen among donors of age bracket 30-40 years.Many publications have shown a close link between iron deficiency and frequency of donation specially highlighted by the famous RISE Study. $(21,22,23)$

Prevalence of anaemia is an important health indicator and when used with other measurements of iron status, the haemoglobin concentration can provide information about the severity of iron deficiency. Incidence of anemia $4.5 \%$ or less in general population comprising children, females and males is considered normal as per WHO guidelines.(24) A study from India has reported prevalence of anemia among prospective blood donors as 1.8\%.(17)Although determination of cause of anemia was a major limitation of our study, its prevalence of $7.8 \%$ selectively among male donors of urban population with predominant microcytic morphology raises questions about the health of the male population in particular. Iron deficiency aside, other epidemiologically important causative factors include infectious and inflammatory disorders, the 
prevalence of genes for thalassaemia, and deficiencies of folic acid and vitamin B12 in certain settings.

The acceptable range of hemoglobin for donor selection varies globally. AABB has set a minimum level of $12.5 \mathrm{mg} / \mathrm{dl}$ for both sexes. Interestingly this level has been brought down in some South Asian countries .According to Standards in Blood Bank and Blood Transfusion Services India [2007] minimum acceptable level of hemoglobin should not be less than 12gm/dl for all.(25)This level is being practiced in some developing countries like Bhutan, where an acute shortage of voluntary donors is a probable explanation.(26) Whether we should follow the international or regional standards is debatable in the absence of studies regarding reference ranges in our population.

To assess donors' health in relation to low hemoglobin and its etiology, more studies are needed. It is the duty of blood bank staff to explain the reasonsand duration of deferrals with proper referrals to concerned clinics for evaluation and treatment. Further, to avoid losing a valuable pool of potential donors to borderline low hemoglobin; some available options are to decrease the cutoff hemoglobin level to $12 \mathrm{~g} / \mathrm{dl}$, with increase in donation interval. Iron replacement therapy for two months post donation may be prescribed to regular donors after establishing iron deficiency. Health policies like iron fortified food to improve the general health of population need to be implemented by the government. 


\section{CONCLUSION}

A significant portion of male replacement donors belonging to urban population are rejected due to low hemoglobin which is mild but predominantly hypochromic microcytic in morphology. Prevalence of anemia among male donors was high at $7.8 \%$.It shows an expected positive correlation with microcytic morphology and adult age group. Further studies from other parts of country are needed to determine the cause and rate of donor rejection due to anemia. Efforts should be targeted towards improving health awareness among replacement donors. Reduction in donor pool can be avoided by recruiting donors with borderline low hemoglobin with concomitant increase in interval for next donation. Iron supplements may be prescribed to donors where cause of anemia is established as iron deficiency. 


\section{REFERENCES}

1. National Blood Policy \& Strategic Framework 2008-2012 for Blood Transfusion Services in Pakistan. [Internet] Government of Pakistan. National AIDS Control Programme Ministry of Health, 2007 [rev. 2014 Oct16;cited 2015Feb 23].Available from:http://www.nacp.gov.pk/introduction/National_Blood_policy_\&_strategic_framewo rk-BT.pdf

2. Fung MK, Grossman BJ, Hillyer C, Westhoff CM eds. AABB Technical Manual. 18th ed. Bethesda (MD): AABB, 2014.

3. World Health Organization: Blood donor Selection: Guidelines on Assessing Donor Suitability for Blood Donation. [Internet] Geneva. (Switzerland) 2012 [[rev. 2014Oct 16; cited 2015 Feb 28].Available from: http://www.who.int/bloodsafety/publications /guide_selection_assessing_suitability.

4. Custer B, Chinn A, Hirschler NV, Busch MP, Murphy EL. The consequences of temporary deferral on future whole blood donation. Transfusion 2007, 47: 1514-23.

5. World Health Organization: Haemoglobin concentrations for the diagnosis of anemia and assessment of severity. [Internet] Geneva. (Switzerland) Vitamin and Mineral Nutrition Information System. 2011 [rev. 2014Dec 15; cited2015 Mar 11] Available from: http://www.who.int/vmnis/indicators/haemoglobin.pdf.

6. Bessman JD, Gilmer PR Jr, Gardner FH. Improved classification of anemias by MCV and RDW. Am J ClinPathol 1983; 80:322-26.

7. Tufail S, Babar F, Ikram N, Raza M, Abdul-Shakoor H. Blood Donors Deferral- Causes. JRMC. 2013; 17:119-21. 
8. Zou S, Musavi F, Notari EP, Rios JA, Trouern-Trend J, Fang CT. Donor deferral and resulting donor loss at the American Red Cross Blood Services, 2001 through 2006. Transfusion. 2008; 48:2531-9.

9. Custer B, Johnson ES, Sullivan SD, Haslet TK, Ramsay SD, Hirscheler NV et al. Quantifying losses to the donated blood supply due to deferral and miscollection. Transfusion. 2004; 44: 1417-26.

10. Arslan O. Whole blood donor deferral rate and characteristics of the Turkish population. Tranfus Med. 2007; 17: 379-83.

11. Bahadur S, Jain S, Goel RK, Pahuja S, Jain M.Analysis of blood donor deferral characteristics in Delhi, India. Southeast Asian J Trop Med Public Health.2009; 40:108791.

12. Custer B, Schlumpf KS, Wright D, Simon TL, Wilkinson S, Ness PM; NHLBI Retrovirus Epidemiology Donor Study-II. Donor return after temporary deferral. Transfus. 2011; 51(6):1188-96.

13. Khan S, Rehman N, Raziq F. Donor deferral: evaluation of causes on pre donor screening. GJMS. 2012; 10:23-6.

14. Di Lorenzo Oliveira C, Loureiro F, de Bastos MR, Proietti FA, Carneiro-Proietti AB. Blood donor deferral in Minas Gerais State, Brazil: blood centers as sentinels of urban population health. Transfusion2009; 49:851-7.

15. Charles KS, Hughes P, Gadd R, Bodkyn CJ, Rodriguez M. Evaluation of blood donor deferral causes in the Trinidad and Tobago National Blood Transfusion Service. Transfus Med. 2010; 20:11-4. 
16. Rabeya Y, Rapiaah M, Rosline H, Ahmed SA, ZaidahWA, Roshan TM. Blood predonation deferrals - a teaching hospital experience. Southeast Asian J Trop Med Public Health 2008; 39: 571-4.

17. Agnihotri N. Whole blood donor deferral analysis at a center in Western India. Asian J Transfus Sci. 2010; 4(2):116-22.

18. Bahadur S, Pujani M, Jain M. Donor deferral due to anemia: A tertiary care center-based study. Asian J Transfus Sci.2011; 5:53-5.

19. Javadzadeh SH, Attar M,Yavari MT .A study of the prevalence of iron deficiency and its related factors in blood donors of Yazd, Iran, 2003.Transfus Med.2005;15:287-93.

20. Da silva MA, de Souza RAV, Carlos AM, Soares S, Moraes-Souza H, Pereira Gde A. Etiology of anemia of blood donor candidates deferred by hematologic screening. Rev Bras Hematol Hemoter.2012;34:356-60.

21. Erhabor O, Imrana S, Buhari HA, Abdulrahaman Y, Wase AA, Ikhuenbor D Aghedo, F. Iron Deficiency among Blood Donors in Sokoto, North Western, Nigeria. OJBD.2014; 4: $33-42$.

22. Cancado RD, Chiattone CS, Alonso FF, Langhi DM, Junior, de Alves RC. Iron deficiency in blood donors. Sao Paulo Med J. 2001; 119:132-4.

23. Cable RG, Glynn SA, Kiss JE, Mast AE, Steele WR, Murphy EL et al. NHLBI Retrovirus Epidemiology Donor Study-IIIron deficiency in blood donors: analysis of enrollment data from the REDS-II Donor Iron Status Evaluation (RISE) study. Transfusion. 2011; 51(3):511-22.

24. World Health Organization: Assessing the iron status of populations: report of a joint World Health Organization/ Centers for Disease Control and Prevention technical 
consultation on the assessment of iron status at the population level, $2^{\text {nd }}$ ed., Geneva, 2007. Available at:http://www.who.int/nutrition/publications/micronutrients/ anaemia_iron_deficiency/9789241596107.pdf

25. National AIDS Control Organization:Standards for Blood Banks \& Blood Transfusion Services. [Internet] New Delhi(India):Ministry of Health and Family Welfare, Government of India;2007 [rev. 2014 Nov 28;cited 2014 Feb16].Available from:http://www.naco.gov.in/upload/FinalPublications/BloodSafety/StandardsforBloodB anksandBloodTransfusionServices.pdf

26. National Standards for Blood Transfusion Service:Blood Safety Program[Internet].Thimphu(Bhutan): Health Care and Diagnostic Division Department of Medical Services Ministry of Health;2013[rev. 1 Jan 2015;cited 20 Jan 2015].Available from: http://www.who.int/bloodsafety/transfusion_services/BhutanNationalStandardsBTServic es.pdf 
Table 1: Demographics of male replacement donors rejected due to low hemoglobin

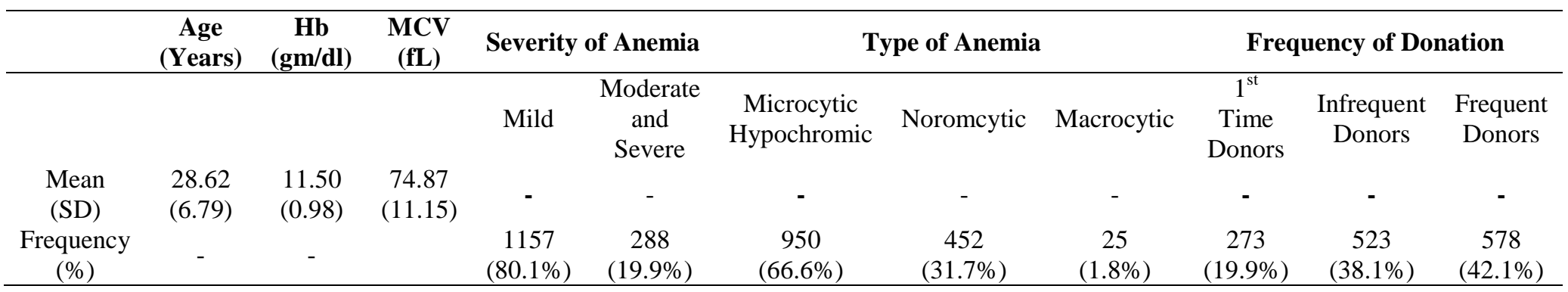

Table 2:

\begin{tabular}{|c|c|c|c|c|c|c|}
\hline & & Spearm & Correlation & & & \\
\hline & Severity & Anemia & Type o & nemia & Frequency & donation \\
\hline & $\begin{array}{l}\text { Correlation } \\
\text { Coefficient }\end{array}$ & P-value & $\begin{array}{l}\text { Correlation } \\
\text { Coefficient }\end{array}$ & P-value & $\begin{array}{l}\text { Correlation } \\
\text { Coefficient }\end{array}$ & P-value \\
\hline Type of Anemia & $-.069^{* *}$ & .009 & & & & \\
\hline Frequency of Donation & .042 & .262 & .002 & .956 & & \\
\hline Age & .012 & .647 & $.149^{* *}$ & .000 & .030 & .428 \\
\hline
\end{tabular}

**. Correlation is significant at the 0.01 level (2-tailed). 